\title{
Comorbid personality disorders and their impact on the presentation of severe dissociative experiences in patients with borderline personality disorder in Mexican patients
}

Andrés Rodríguez-Delgado, Edgar Miranda, Iván Arango de Montis

Clínica de Trastorno Límite de la Personalidad, Instituto Nacional de Psiquiatría Ramón de la Fuente Muñíz, Mexico City, Mexico.

Ana Fresán, Ruth Alcalá-Lozano

Subdirección de Investigaciones Clínicas, Instituto Nacional de Psiquiatría Ramón de la Fuente Muñíz, Mexico City, Mexico.

Eduardo A. Garza-Villarreal

Subdirección de Investigaciones Clínicas, Instituto Nacional de Psiquiatría Ramón de la Fuente Muñíz, Mexico City, Mexico.

Center of Functionally Integrative Neuroscience, University of Aarhus, Denmark.

Xochitl Duque-Alarcón

Clínica de Especialidades en Neuropsiquiatría, Instituto de Seguridad y Servicios Sociales de los Trabajadores del Estado (ISSSTE), Mexico City, Mexico.

Thania Balducci

Facultad de Medicina, Universidad Nacional Autónoma de México, Mexico City, Mexico. 
Subdirección de Investigaciones Clínicas, Instituto Nacional de Psiquiatría Ramón de la Fuente Muñíz, Mexico City, Mexico.

Author Note

Andrés Rodríguez-Delgado, Clínica de Trastorno Límite de la Personalidad, Instituto Nacional de Psiquiatría Ramón de la Fuente Muñíz, Mexico City, Mexico; Ana Fresán, Subdirección de Investigaciones Clínicas, Instituto Nacional de Psiquiatría Ramón de la Fuente Muñíz, Mexico City, Mexico; Edgar Miranda, Clínica de Trastorno Límite de la Personalidad, Instituto Nacional de Psiquiatría Ramón de la Fuente Muñíz, Mexico City, Mexico; Eduardo A. Garza-Villarreal, Subdirección de Investigaciones Clínicas, Instituto Nacional de Psiquiatría Ramón de la Fuente Muñíz, \& Center of Functionally Integrative Neuroscience, University of Aarhus, Aarhus, Denmark; Ruth Alcalá-Lozano, subdirección de Investigaciones Clínicas, Instituto Nacional de Psiquiatría Ramón de la Fuente Muñíz, Mexico City, Mexico; Xóchitl Duque-Alarcón, Clínica de Especialidades en Neuropsiquiatría, Instituto de Seguridad y Servicios Sociales de los Trabajadores del Estado (ISSSTE), Mexico City, Mexico; Thania Balducci, Facultad de Medicina, Universidad Nacional Autónoma de México, Mexico City, Mexico \& Subdirección de Investigaciones Clínicas, Instituto Nacional de Psiquiatría Ramón de la Fuente Muñí; Iván Arango de Montis, Clínica de Trastorno Límite de la Personalidad, Instituto Nacional de Psiquiatría Ramón de la Fuente Muñíz, Mexico City, Mexico.

Correspondence concerning this article should be adressed to Iván Arango de Montis, Clínica de Trastorno Límite de la Personalidad, Instituto Nacional de Psiquiatría Ramón de la Fuente Muñíz, Mexico City, 14370. E-mail: iadmontis@gmail.com 


\begin{abstract}
The objective of this study was to identify personality disorders comorbid to BPD that confer greater risk for the presence of severe dissociative experiences. Three hundred and one outpatients with a primary diagnosis of BPD were evaluated using the Structured Clinical Interview for DSM-IV Axis II personality disorders (SCID-II), the Borderline Evaluation of Severity Over Time (BEST) and the Dissociative Experiences Scale (DES). Our results show that the most frequent personality disorders comorbid to BPD were paranoid $(83.2 \%, \mathrm{n}=263)$ and depressive $(81.3 \%, \mathrm{n}=257)$. On average, the patients scored with 43.3 points and 28.6 points in the BEST and DES scales respectively. We categorized the sample into patients with and without severe dissociative experiences (41\% were positive). A logistic regression model revealed that Schizotypal, Obsessive-compulsive and Antisocial personality disorders conferred greater risk for the presence of severe dissociative experiences. The results suggest that a large proportion of patients with BPD present a high rate of severe dissociative experiences and that some clinical factors such as personality comorbidity confer greater risk for dissociation, which is related to greater dysfunction and suffering, as well as a worse progression of the BPD.
\end{abstract}

\title{
Keywords
}

Comorbid personality disorders; Dissociation; Borderline personality disorder; Personality disorders; Dissociative experiences. 


\section{Introduction}

Borderline personality disorder (BPD) is a serious psychiatric condition characterized by the presence of affective instability, impulsivity, chaotic interpersonal relationships and identity disturbances, which causes alterations in multiple functioning areas (APA, 2013). BPD is considered a common disorder that affects from $0.5 \%$ to $5.9 \%$ of the general population (Grant, Chou, Goldstein \& al., 2008), and is more commonly present in women; however, this evidence has not been consistent (Leichsenring, Leibing, Kruse, New, \& Leweke, 2011). In clinical psychiatric populations, BPD is the most common personality disorder, with a prevalence of $10 \%$ of all psychiatric outpatients and between $15 \%$ and $25 \%$ of inpatients (Torgersen, 2005 ; Gunderson, 2009). About $80 \%$ of patients with BPD have a co-occurrent personality disorder (PD) (Zanarini, Frankenburg, Dubo, Sickel, Trikha, Levin, \& Reynolds, 1998). The most frequent PD reported in BPD are as follows: 1) from cluster A, Paranoid PD has been reported in $30-38 \%$; 2) from cluster B the Antisocial and Histrionic PD has been reported in $13-19 \%$ and in 15-25\%, respectively; and 3) from cluster C, Dependent and Avoidant PD in 30-50\% and in 2040\%, respectively (Koenigsberg, Harvey, Mitropoulou, Schmeidler, New, Goodman,... \& Siever, 2002; Grant, Chou, Goldstein, \& al., 2008; Barrachina, Pascual, Ferrer, Soler, Rufat, Andión, ... \& Pérez, 2011).

In addition, BPD patients frequently report dissociative experiences such as unexplained changes in mood, identity confusion, absorption, derealization, depersonalization and amnesia (Korzekwa, Dell, Links, Thabane, \& Fougere, 2009). Dissociative symptoms occur in about two thirds of patients with BPD (Korzekwa, Dell, \& Pain; 2009). Further, the level of dissociation is significantly higher in BPD than in healthy controls, general psychiatric patients and patients 
COMORBID PD AND DISSOCIATIVE EXPERIENCES IN BPD

with other personality disorders. In fact, only patients with dissociative disorders present greater rates of dissociative symptoms than patients with BPD (Zanarini, Ruser, Frankenburg, Hennen, \& Gunderson, 2000; Carlson, \& Putnam, 1993). It has been suggested that the phenomenon of dissociation within BPD seems to constitute a continuum of severity (Scalabrini, Cavicchioli, Fossati, \& Maffei, 2017). Using the Dissociative Experiences Scale (DES), Zanarini and colleagues (2000) found that more than a quarter of the patients experienced severe dissociative symptoms. The presence of dissociative symptoms in BPD has been positively correlated with greater comorbidity with other psychiatric disorders; greater frequency, length and earlier age at time of hospitalizations; greater behavioral lack of control, and more frequent self-injurious behavior (Korzekwa, Dell, \& Pain; 2009).

PD and comorbid dissociative experiences may worsen the emotional and behavioral manifestation during the course of BPD, thus hindering treatments and functional reintegration of these patients to daily life. It is therefore, necessary to increase our knowledge about how PD comorbidity may affect the overt manifestation of severe dissociative experiences in this population. The aim of the present study was to identify the most important comorbid personality and to determine if these comorbid PDs are predictors of severe dissociative experiences in patients with BPD.

\section{Method}

\section{Patients}

This was a retrospective design with the use of the institutional clinical databases. We included the demographic and clinical data from all male and female patients between 17 and 65 years of age who entered the Borderline Personality Disorder Clinic at the Instituto Nacional de 
COMORBID PD AND DISSOCIATIVE EXPERIENCES IN BPD

Psiquiatría Ramón de la Fuente Muñiz (INPRF) located in Mexico City, between October 2015 and February 2018, and who had the confirmed diagnosis of BPD according to Diagnostic and Statistical Manual of Mental Disorders IV-TR (DSM-IV-TR) (APA, 1994). Patients with mean diagnosis of Antisocial PD, Psychotic Disorders, Bipolar Disorder, active Eating Disorder or Substance Dependence (except Nicotine Dependence) were excluded. This study was conducted according to the Declaration of Helsinki and was approved by ethics and research committee of the INPRF (INPDSCEC-02-20.1). All patients gave their oral and written consent that their data could be used for research purposes.

\section{Measurement instruments and procedure}

Patients who met the criteria for admission to the BPD Clinic were evaluated according to the Clinic's protocol, which includes obtaining general demographic data and a clinical evaluation through an interview conducted by a psychiatrist at the Clinic. This evaluation is complemented with the application of several scales and questionnaires. For the present study, the self-report screening questionnaire of the Structured Clinical Interview for DSM-IV Axis II personality disorders (SCID-II), followed by a clinical interview, was used to assess the diagnosis of BPD and the presence of other comorbid PD (First, Spitzer, Gibbon, Williams, \& Benjamin, 1994). The overall severity of the BPD in the 30 days prior to the interview was evaluated with the Borderline Evaluation of Severity Over Time (BEST), a self-report instrument of 15 items rated in a Likert type format of five points (Pfohl, Blum, St. John, McCormick, Allen, \& Black, 2009). The Dissociative Experiences Scale (DES), which consists of 28 selfreport items evaluated on a visual analog scale from 0 to 100 , was used to assess the presence and severity of the dissociative experiences (Bernstein, \& Putnam, 1986). We used a score of 30 
COMORBID PD AND DISSOCIATIVE EXPERIENCES IN BPD

or more as an indicator of severe dissociative experience as Zanarini and colleagues (2000). This score was used to divide the sample between those with and without severe dissociative experiences (SDE).

\section{Statistical Analysis}

Demographic and clinical characteristics were described with frequencies and percentages for categorical variables and means and standard deviations (S.D.) for continuous variables. The comparisons between patients with and without SDE, were done using Chi-square tests $\left(\mathrm{x}^{2}\right)$ for categorical variables and with Independent Sample t Tests for continuous variables.

Variables where significant differences arise in the comparative analyses were included in a logistic regression analysis to determine the risk conferred by demographic variables and the presence of comorbidity PD in the presentation SDE. The Aikake Information Criterion (AIC) was determined to identify the most appropriate regression model for the present sample. The level of statistical significance was set at $\mathrm{p}<0.05$.

\section{Results}

A total of 316 patients with BPD were included in the study, of which $85.8 \%(n=271)$ were female with an average age of 29.7 years (S.D.=10.5, range 17-62). A large percentage of patients had completed their high-school studies $(48.4 \%, n=153)$, followed by those with a bachelor's degree $(32.6 \%, n=103)$, completed junior high school $(14.2 \%, n=45)$, elementary school $(2.5 \%, n=8)$ and less frequently, postgraduate studies $(2.2 \%, n=7)$. Twelve patients did not complete the BEST scale, therefore, we reported the data obtained with 304 patients, whose average score was 43.3 points (S.D. $=11.4$, range $15-69)$ indicative of a moderate symptom 
COMORBID PD AND DISSOCIATIVE EXPERIENCES IN BPD

severity. In the same way, fourteen patients did not complete the DES scale; thus, the average severity score of the dissociative experiences of the remaining 301 patients in the sample was of 28.6 points (S.D.=19.8, range $0-98)$. Using the cut-off point of $30,41.9 \%(n=126)$ of the patients were classified with SDE.

The most frequent comorbid PDs were: 1) Paranoid PD (83.2\%, n=263) and 2) Depressive ( $81.3 \%, \mathrm{n}=257)$, while those with the lowest presentation were: 3 ) Schizotypal $(25.6 \%, n=81)$ and 4) Antisocial $(37.0 \%, n=117)$. The comparisons of demographic characteristics and comorbidity with PDs among patients with and without SDE are displayed in Table 1. Both groups were similar in terms of sex, age and level of education. BPD patients with Schizoid, Schizotypal, Antisocial, Obsessive-compulsive, and Passive-aggressive comorbidities presented SDE more often. In addition, patients with SDE reported greater severity of BPD symptoms.

Five comorbid PDs and the total score of the BEST scale were included in the logistic regression model. The logistic regression equation correctly classified $66.7 \%$ of the cases and was significant for the present sample according to the Hosmer and Lemeshow statistical value $(p=0.98)$. As shown in Table 2, the main predictors of SDE were the presence of Antisocial PD, Obsessive-compulsive and Schizotypal, conferring risks of 1.80, 2.44 and 3.44 times higher, respectively, for the presentation of SDE. This logistic regression model was adequate according to the reduction observed in the AIC values.

\section{Discussion}

In this study PD comorbidity was a common finding, confirming that BPD as the only 
COMORBID PD AND DISSOCIATIVE EXPERIENCES IN BPD

diagnosis is a rare condition to find. We found that Paranoid, Depressive and Passive-aggressive PDs were the most common comorbidities, and that Antisocial and Schizotypal were the least common ones. This finding contrasts with other studies that have shown Schizotypal, Narcissistic and Dependent as the most frequent PDs comorbid with BPD (Tomko, Trull, Wood, \& Sher, 2014). We found rates of PDs somewhat higher than the ones reported in the literature, which could be explained by the fact that we used a self-report measure. It had been suggested that some methodological factors including the source of the information and the instrument used for the assessment could inflate PDs estimates, and self-administered questionnaires are more prone to this bias (Zimmerman, Rothschild, \& Chelminski, 2005). Although in our study we observed that the Antisocial PD is one of the less frequent comorbid diagnosis, it was presented in $37 \%$ of the sample, which represents a higher rate than reported in other investigations with ranges between 13\% and 19\% (Grant, Chou, Goldstein, \& al., 2008; Koenigsberg, Harvey, Mitropoulou, Schmeidler, New, Goodman,... \& Siever, 2002) suggesting the possibility that we were dealing with a group of patients with severe psychopathology.

The mean DES score in our study (28.6 total score) is higher than the mean other authors have reported (23.7 total score) in studies with BPD patients (Laddis, \& Dell, 2002), but lower than other studies (44.4 total score) where $64 \%$ of the BPD sample met criteria for an additional diagnosis of dissociative disorder (Sar, Kundakci, Kiziltan, Yargiç, Tutkun, Bakim, Bozkurt, Ozpulat, Keser, \& Ozdemir, 2003). More than $40 \%$ of our patients presented SDE, which represents a much higher percentage than the ones reported in other studies. For example, Zanarini and colleagues (2000) found that $26 \%$ of a sample of inpatients with diagnosis of BPD presented SDE. This is interesting since our sample were outpatients and SDE had been correlated with greater stress and poorer functioning, much more related to the assessment of 
inpatients (Korzekwa, Dell, Links, Thabane, \& Fougere, 2009). One possible explanation could be that Zanarini and colleagues (2000) used an instrument based on DSM-III-R, a diagnostic system that did not include the item 9 about transient, stress-related dissociative symptoms, which was added to the diagnostic criteria for BPD in the DSM-IV and perhaps a significant proportion of our sample could present a dissociative disorder comorbid with BPD and not only high dissociative experiences (APA, 1987; APA, 1994). Even though, BPD criterion 9 in the DSM-IV and DSM-5 mention that the presence of dissociative symptoms are of sufficient severity or duration to warrant an additional diagnosis, it has been argued that this is an unspecific rule for deciding when dissociative symptoms represent a separate dissociative disorder diagnosis or can be considered as a BPD criterion (APA, 1994; APA, 2013; Scalabrini, Cavicchioli, Fossati, \& Maffei, 2017). Unfortunately, we did not assess the presence of dissociative disorders in the present research, which is one of the main limitations in our study.

We found that Antisocial PD, Obsessive-compulsive and Schizotypal PD predicted the presence of SDE in patients with main diagnosis of BPD. Studies about risk factors of dissociation in BPD have suggested that the BPD syndrome itself represents a risk factor for the occurrence of dissociative phenomena (Zanarini, Ruser, Frankenburg, Hennen, \& Gunderson, 2000). In this sense, we also found that higher severity of borderline personality symptoms predicts SDE. Studies about subgroups in BPD patients with respect to the intensity of the dissociative symptoms have suggested that dissociation could be a heterogeneous phenomenon within BPD, and the presence and severity of traumatic experience during the development may be a frequently associated factor (Zanarini, Frankenburg, Jager Hyman, Reich, \& Fitzmaurice, 2008; Korzekwa, Dell, Links, Thabane, \& Fougere, 2009; Scalabrini, Cavicchioli, Fossati, \& Maffei, 2017). Semiz and colleagues (2007) demonstrated a predictive role of childhood trauma, 
COMORBID PD AND DISSOCIATIVE EXPERIENCES IN BPD

particularly physical abuse and early separation, for the severity of dissociative symptoms in Antisocial PD patients. This is consistent with the traumagenic model of dissociation, which postulates that different types of trauma influence the expression of the dissociative phenomenon, which can be seen as a psychological defense against the full impact of these experiences (Putman, 1995; Goodman, Weiss, Mitropoulou, New, Koenigsberg, Silverman, \& Siever, 2003). Moreover, the states of consciousness model of dissociation proposes that some dissociative experience such as memory disturbance and fragmentation of the self, represent disturbances in the capacity to modulate the state of consciousness and integrate the self as a result of trauma (Putman, 1991; Goodman, Weiss, Mitropoulou, New, Koenigsberg, Silverman, \& Siever, 2003). Some authors have considered that a history of psychological trauma could favor the development of perceptions and beliefs characteristics of the Schizotypal (Berenbaum, Thompson, Milanak, Boden, \& Bredemeier, 2008) and Obsessive compulsive PD. Studies in clinical samples have shown a relationship between Schizotypal and Obsessive-compulsive PDs with a history of traumatic events (Yen, Shea, Battle, Johnson, Zlotnick, Dolan-Sewell, \& Zanarini, 2002). In fact, it has been considered that dissociative symptoms tend to mediate the link between antecedents of maltreatment and schizotypal symptoms (Berenbaum, Thompson, Milanak, Boden, \& Bredemeier, 2008). Most of these studies do not explore the comorbidity between Antisocial, Obsessive-compulsive or Schizotypal PD with BPD and therefore, it is difficult to extrapolate these findings with those obtained in our study. Also, we did not assess maltreatment, abuse or trauma experience background, and therefore, it is not possible to reach similar conclusions. However, this provides further knowledge and evidence for the assessment of these variables in everyday clinical practice. 


\section{COMORBID PD AND DISSOCIATIVE EXPERIENCES IN BPD}

The section III of DSM-5 has included an alternative model for diagnosis personality disorders, which assesses personality pathology as dimensions considering alterations in the self (identity and self direction) and interpersonal functioning (empathy and intimacy) (APA, 2013). This view is related with the perspective of structural personality organization, a psychodynamic model based on object relations theory, in which borderline personality organization (BPO) is defined by the presence of alterations in identity, use of primitive defensive mechanisms and some alterations in reality testing during extreme distress. From this perspective, BPO includes some of the most severe personality disorders and allows the assessment of the severity of the personality pathology and affiliation (introversion vs. extraversion). In sum, structural personality organization model combines a dimensional perspective of the severity and allows a categorical classification of the personality pathology (Kernberg, \& Caligor, 2005; Clarkin, Cain, \& Lenzenweger, 2017; Esguevillas, Díaz-Caneja, Arango, del Rey-Mejías, Bernardo, Delgado,... \& Carrasco, 2017). The fact that we observed that BPD comorbid with Schizotypal and Antisocial pathology predicts SDE is consistent with the structural personality model in which, patients with diagnosis of BPD with schizotypal characteristics would present the highest severity of personality pathology on the side of the introversion, and patients with diagnosis of BPD with antisocial characteristics would show the highest severity of personality pathology on the side of the extraversion, and therefore, more identity alterations, use of primitive defenses and manifestations of ego weakness and consequently, higher dissociative experience.

There are some limitations in this study. The differences in the means and proportion of the comorbidity with PD in subject with BPD observed in our study could be due to methodological factors such as sampling, diagnostic instruments, DSM version and clinical setting where the assessment was done, as some researches and author has been suggested 
COMORBID PD AND DISSOCIATIVE EXPERIENCES IN BPD

(Grant, Chou, Goldstein, \& al., 2008; Barrachina, Pascual, Ferrer, Soler, Rufat, Andión, ... \&

Pérez, 2011). Others limitations were the lack of systematic exploration of posttraumatic stress disorder, history of trauma and abuse and dissociative disorders as these conditions present a high co-occurrence with BPD and are associated with a higher severity of dissociative experiences.

Nevertheless, our study provides further evidence regarding the complexity and heterogeneity of the dissociative phenomenon presented in the BPD. The possibility of knowing the clinical factors such as personality comorbidity, that confer greater risk for dissociation, which is associated with great dysfunction and suffering, as well as a worse trajectory in the BPD is of importance for the early identification of people with a more discouraging prognosis and in that sense, the possibility of carrying out early interventions and make more specific treatment decisions, considering that patients who use this defensive phenomenon present behaviors that interfere in their functioning that in therapy for example, result in distortions in the therapist-patient interaction.

\section{References}

American Psychiatric Association. (1987). Diagnostic and statistical manual of mental disorders; revised (DSM-III-R). Washington DC. 
COMORBID PD AND DISSOCIATIVE EXPERIENCES IN BPD

American Psychiatric Association. (1994). Diagnostic and statistical manual of mental disorders (DSM-IV-TR). American Psychiatric Pub.

American Psychiatric Association. (2013). Diagnostic and statistical manual of mental disorders (DSM-5®). American Psychiatric Pub.

Barrachina, J., Pascual, J. C., Ferrer, M., Soler, J., Rufat, M. J., Andión, O., ... \& Pérez, V. (2011). Axis II comorbidity in borderline personality disorder is influenced by sex, age, and clinical severity. Comprehensive psychiatry, 52(6), 725-730.

Berenbaum, H., Thompson, R. J., Milanak, M. E., Boden, M. T., \& Bredemeier, K. (2008). Psychological Trauma and Schizotypal Personality Disorder. Journal of Abnormal Psychology, 117(3), 502-519.

Bernstein, E. M., \& Putnam, F. W. (1986). Development, reliability, and validity of a dissociation scale. Journal of nervous and mental disease.

Carlson, E. B., \& Putnam, F. W. (1993). An update on the dissociative experiences scale. Dissociation: progress in the dissociative disorders.

Clarkin, J. F., Cain, N. M., \& Lenzenweger, M. F. (2017). Advances in Transference-Focused Psychotherapy Derived from the Study of Borderline Personality Disorder: Clinical Insights With a Focus on Mechanism. Current opinion in psychology.

Esguevillas, Á., Díaz-Caneja, C. M., Arango, C., Del Rey-Mejías, Á. L., Bernardo, E. G., Delgado, C., ... \& Carrasco, J. L. (2017). Personality organization and its association with clinical and functional features in borderline personality disorder. Psychiatry research, 
COMORBID PD AND DISSOCIATIVE EXPERIENCES IN BPD

262, 393-399.

First, M., Spitzer, R., Gibbon, M., Williams, J. \& Benjamin, L. (1994). Structured Clinical Interview for DSM-IV Axis II personality disorders (SCID II). New York: Biometric Research Department.

Grant, B.F., Chou, S.P., Goldstein, R.B., \& al. (2008). Prevalence, correlates, disability, and comorbidity of DSM-IV borderline personality disorder: results from the Wave 2 National Epidemiologic Survey on Alcohol and Related Conditions. The Journal of clinical psychiatry, 69 (4), 533-45.

Goodman, M., Weiss, D. S., Mitropoulou, V., New, A., Koenigsberg, H., Silverman, J. M., \& Siever, L. (2003). The relationship between pathological dissociation, self-injury and childhood trauma in patients with personality disorders using taxometric analyses. Journal of trauma \& dissociation, 4(2), 65-88.

Gunderson, J. G. (2009). Borderline personality disorder: ontogeny of a diagnosis. American Journal of Psychiatry, 166(5), 530-539.

Kernberg, O. F., \& Caligor, E. (2005). A psychoanalytic theory of personality disorders. In Major theories of personality disorder, edn 2. Edited by Lezenweger, M.F., Clarkin, J.F. Guilford Press; 114-156.

Koenigsberg, H. W., Harvey, P. D., Mitropoulou, V., Schmeidler, J., New, A. S., Goodman, M., ... \& Siever, L. J. (2002). Characterizing affective instability in borderline personality disorder. American Journal of Psychiatry, 159(5), 784-788. 
COMORBID PD AND DISSOCIATIVE EXPERIENCES IN BPD

Korzekwa, M. I., Dell, P. F., Links, P. S., Thabane, L., \& Fougere, P. (2009). Dissociation in borderline personality disorder: A detailed look. Journal of Trauma \& Dissociation, 10(3), 346-367.

Korzekwa, M. I., Dell, P. F., \& Pain, C. (2009). Dissociation and borderline personality disorder: an update for clinicians. Current psychiatry reports, 11(1), 82-88.

Laddis, A., \& Dell, P. F. (2002, November). A comparison of DID with 30 cases of SIDP-IV diagnosed borderline personality disorder. In annual meeting of the International Society for the Study of Dissociation, Baltimore, MD.

Leichsenring, F., Leibing, E., Kruse, J., New, A.S., \& Leweke, F. (2011). Borderline personality disorder. The Lancet, 377(9759), 74-84

Pfohl, B., Blum, N., St. John, D., McCormick, B., Allen, J., \& Black, D. W. (2009). Reliability and validity of the Borderline Evaluation of Severity Over Time (BEST): A self-rated scale to measure severity and change in persons with borderline personality disorder. Journal of personality disorders, 23(3), 281-293.

Putnam, F. W. (1991). Dissociative phenomena. In A. Tasman \& S. M. Goldfinger (Eds.), American Psychiatric Press review of psychiatry, Vol. 10, (pp. 145-160). Arlington, VA, US: American Psychiatric Association.

Putnam, F.W. (1995). Development of dissociative disorders. In D. Ciccheti \& D.J. Cohen (Eds.), Development psychopathology. Vol. 2. Risk, disorder and adaption. (pp. 581-608). New York: Wiley. 
COMORBID PD AND DISSOCIATIVE EXPERIENCES IN BPD

Sar, V., Kundakci, T., Kiziltan, E., Yargiç , I.L., Tutkun, H., Bakim, B., Bozkurt, O., Ozpulat, T., Keser, V., \& Ozdemir, O. (2003). The Axis-I dissociative disorder comorbidity of borderline personality disorder among psychiatric outpatients. Journal of Trauma \& Dissociation, 4(1), 119-136.

Scalabrini, A., Cavicchioli, M., Fossati, A., \& Maffei, C. (2017). The extent of dissociation in borderline personality disorder: A meta-analytic review. Journal of Trauma \& Dissociation, 18(4), 522-543.

Semiz, U. B., Basoglu, C., Ebrinc, S., \& Cetin, M. (2007). Childhood trauma history and dissociative experiences among Turkish men diagnosed with antisocial personality disorder. Social psychiatry and psychiatric epidemiology, 42(11), 865-873.

Tomko, R. L., Trull, T. J., Wood, P. K., \& Sher, K. J. (2014). Characteristics of borderline personality disorder in a community sample: comorbidity, treatment utilization, and general functioning. Journal of personality disorders, 28(5), 734-750.

Torgersen, J. (2005). Epidemiology. In: Oldham, J., Skodol, A.E., Bender, D.S., Textbook of personality disorders. Washington, DC: American Psychiatric Publishing, 129-41.

Yen, S., Shea, M. T., Battle, C. L., Johnson, D. M., Zlotnick, C., Dolan-Sewell, R., ... \& Zanarini, M. C. (2002). Traumatic exposure and posttraumatic stress disorder in borderline, schizotypal, avoidant, and obsessive-compulsive personality disorders: Fingings from the collaborative longitudinal personality disorders study. The Journal of nervous and mental disease, 190(8), 510-518. 
COMORBID PD AND DISSOCIATIVE EXPERIENCES IN BPD

Zanarini, M. C., Frankenburg, F. R., Dubo, E. D., Sickel, A. E., Trikha, A., Levin, A., \& Reynolds, V. (1998). Axis I comorbidity of borderline personality disorder. American Journal of Psychiatry, 155(12), 1733-1739.

Zanarini, M. C., Ruser, T., Frankenburg, F. R., \& Hennen, J. (2000). The dissociative experiences of borderline patients. Comprehensive psychiatry, 41(3), 223-227.

Zanarini, M. C., Ruser, T. F., Frankenburg, F. R., Hennen, J., \& Gunderson, J. G. (2000). Risk factors associated with the dissociative experiences of borderline patients. The Journal of nervous and mental disease, 188(1), 26-30.

Zanarini, M. C., Frankenburg, F. R., Jager-Hyman, S., Reich, D. B., \& Fitzmaurice, G. (2008). The course of dissociation for patients with borderline personality disorder and axis II comparison subjects: a 10-year follow-up study. Acta Psychiatrica Scandinavica, 118(4), 291-296.

Zimmerman, M., Rothschild, L., \& Chelminski, I. (2005). The prevalence of DSM-IV personality disorders in psychiatric outpatients. American Journal of Psychiatry, 162(10), 1911-1918. 
COMORBID PD AND DISSOCIATIVE EXPERIENCES IN BPD

Table 1

Demographic and clinical characteristics between patients with and without severe dissociative experiences (SDE).

\begin{tabular}{|c|c|c|c|c|c|c|c|}
\hline & \multicolumn{2}{|c|}{ Total * } & \multicolumn{2}{|c|}{$\begin{array}{l}\text { Without } \\
\text { SDE } \\
n=175\end{array}$} & \multicolumn{2}{|c|}{$\begin{array}{l}\text { With } \\
\text { SDE } \\
n=126\end{array}$} & \multirow[t]{2}{*}{ Statistics } \\
\hline Demographic & $n$ & $\%$ & & & & & \\
\hline Sex - Women & 257 & 85.4 & 148 & 84.6 & 109 & 86.5 & Fisher $=0.74$ \\
\hline Education - High-school & 145 & 48.2 & 84 & 48.0 & 61 & 48.4 & Fisher $=1.00$ \\
\hline Personality Disorder & $n$ & $\%$ & & & & & \\
\hline Avoidant & 229 & 76.1 & 129 & 73.7 & 100 & 79.4 & Fisher $=0.27$ \\
\hline Dependent & 124 & 41.2 & 65 & 37.1 & 59 & 46.8 & Fisher $=0.09$ \\
\hline Obsessive-compulsive & 236 & 78.4 & 125 & 71.4 & 111 & 88.1 & Fisher $=0.001$ \\
\hline Passive-aggressive & 241 & 80.1 & 129 & 73.7 & 112 & 88.9 & Fisher $=0.001$ \\
\hline Depressive & 249 & 82.7 & 139 & 79.4 & 110 & 87.3 & Fisher $=0.08$ \\
\hline Paranoid & 250 & 83.1 & 139 & 79.4 & 111 & 88.1 & Fisher $=0.06$ \\
\hline Schizotypal & 79 & 26.2 & 27 & 15.4 & 52 & 41.3 & Fisher $<0.001$ \\
\hline Schizoid & 189 & 62.8 & 99 & 56.6 & 90 & 71.4 & Fisher $=0.01$ \\
\hline Histrionic & 144 & 47.8 & 80 & 45.7 & 64 & 50.8 & Fisher $=0.41$ \\
\hline Narcissistic & 205 & 68.1 & 112 & 64.0 & 93 & 73.8 & Fisher $=0.08$ \\
\hline \multirow[t]{2}{*}{ Antisocial } & 113 & 37.5 & 51 & 29.1 & 62 & 49.2 & Fisher $<0.001$ \\
\hline & \multicolumn{4}{|c|}{ Mean S.D. } & & & \\
\hline Age & 29.7 & 10.5 & 30.4 & 10.6 & 28.2 & 9.7 & $\mathrm{t}=1.7, \mathrm{p}=0.07$ \\
\hline BEST scale & 43.3 & 11.4 & 41.0 & 10.8 & 47.0 & 11.1 & $\mathrm{t}=-4.6, \mathrm{p}<0.001$ \\
\hline
\end{tabular}


COMORBID PD AND DISSOCIATIVE EXPERIENCES IN BPD

Table 2

Final logistic regression model for the prediction of severe dissociative experience (SDE) in BPD patients.

$\beta \quad$ OR $\quad 95 \%$ C.I. $\quad p$

AIC value from 348.7 to 316.8

\begin{tabular}{lllll}
\hline Higher BEST scoring & 0.042 & 1.04 & $1.01-1.06$ & 0.001 \\
Antisocial PD & 0.59 & 1.80 & $1.06-3.04$ & 0.02 \\
Schizotypal PD & 1.23 & 3.44 & $1.92-6.17$ & $<0.001$ \\
Obsessive-compulsive PD & 0.89 & 2.44 & $1.24-4.79$ & 0.009 \\
\hline
\end{tabular}

